\title{
Analisis Voltage Drop Pada Jaringan Tegangan Rendah Dengan Metode Pecah Beba Pada Gardu KH 007 Di PT PLN (Persero) UP3 Pamekasan
}

\author{
Denny Rusmansyah; I Ibnu Hajar²; Nurmiati Pasra ${ }^{3}$ \\ ${ }^{1}$ Alumni Teknik Elektro, Fakultas Ketenagalistrikan dan Energi Terbarukan, \\ Institut Teknologi PLN \\ 2, ${ }^{3}$ Teknik Elektro, Fakultas Ketenagalistrikan dan Energi Terbarukan, \\ Institut Teknologi PLN \\ 1'dennyrusmansyah@gmail.com
}

\begin{abstract}
In the operation of the electric power system, good quality service is needed. One of them is the voltage value received by the customer does not get a voltage drop. Based on SPLN No.1: 1978, the service voltage is a maximum of $5 \%$ and a minimum of $10 \%$ of the nominal voltage of the Low Voltage Network that is 220 Volt. One of the locations experiencing voltage drop problems is on the Central Pakandangan Village, Sumenep. Based on an analysis do by the PT PLN UP3 Pamekasan Network division, it turns out that the voltage drop that occurred on Central Pakandangan Village caused by the location. The location is to far from the KH 007 distribution substation, which is 643 meters. Then, the area around the location also has a high burden due to the many standing residential settlements. Therefore, it is necessary to break the load on the network. This method is done by moving or transferring part of the load from the old network to the new network. Which is the last 5 poles in this line. so the load supported by one line does not have voltage drop. The result obtained after performing the load break is that the voltage on the receiving side rises to phase R 200 Volt, phase S 212 Volt, and phase T 202 Volt. Where previously the value of the voltage on the receiving side is phase $R 189$ Volt, phase $S 206$ Volt, and phase T 194 Volt.
\end{abstract}

Keywords: Voltage Drop, Current Load Break Method, Low Voltage

\begin{abstract}
ABSTRAK
Pada sistem pengoperasian tenaga listrik, kita memerlukan adanya kualitas pelayanan yang baik. Salah satu contohnya yaitu memberikan nilai tegangan yang baik kepada pelanggan dan tidak adanya gangguan voltage drop. Berdasarkan SPLN No 1 : 1978, tegangan pelayanan maksimum 5\% dan minimumnya 10\% dari tegangan nominal ideal jaringan tegangan rendah yaitu 220 Volt. Salah satu lokasi yang mengalami gangguan voltage drop adalah Desa Pakandangan Tengah, Sumenep. Berdasarkan hasil analisa yang telah dilakukan oleh petugas divisi jaringan PT PLN UP3 Pamekasan, ternyata voltage drop yang terjadi di Desa Pakandangan Tengah diakibatkan oleh jauhnya lokasi tersebut dari gardu KH 007 yang mensuplai listriknya, jaraknya yaitu 643 meter. Kemudian, daerah disekitaran lokasi tersebut juga memiliki beban beban yang tinggi dikarenakan banyaknya berdiri pemukiman warga. Oleh karena itu, perlu dilakukannya perbaikan di daerah tersebut dengan menggunakan metode pecah beban. Metode ini dilakukan dengan cara
\end{abstract}




\section{JURNAL ILMIAH SUTET}

Vol. 10, No. 2, Desember 2020, P-ISSN 2356-1505, E-ISSN 2656-9175

https://doi.org/10.33322/sutet.v10i2.1306

memindahkan beban dijaringan yang lama ke jaringan yang baru, dimana jaringan yang dipindah yaitu 5 tiang terakhir pada jurusan ini, sehingga beban yang di topang oleh satu jurusan tersebut tidak mengalami voltage drop. Hasil yang didapat setelah melakukan pecah beban yaitu tegangan pada sisi terima naik menjadi di fasa R 200 Volt, fasa S 212 Volt, dan fasa T 202 Volt. Dimana sebelumnya nilai dari tegangan pada sisi terimanya yaitu fasa R 189 Volt, fasa S 206 Volt, dan fasa T 194 Volt.

Kata kunci: Voltage Drop, Pecah Beban, Tegangan Rendah 


\section{PENDAHULUAN}

Jatuh tegangan sendiri pada jaringan tegangan rendah atau JTR disebabkan oleh beberapa kondisi, contohnya seperti sambungan antara kabel SR (Sambungan Rumah) dan kabel JTR nya tidak sempurna, jauhnya jarak antara gardu distribusi dengan rumah pelanggan yang disupplay, beban beban yang tinggi pada suatu jaringan, dan juga luas penampang penghantarnya yang terlalu kecil. Berdasarkan SPLN No.1 tahun 1978, tegangan pelayanan memiliki nilai maksimum yaitu diangka $5 \%$ atau 231 Volt dan minimum $10 \%$ atau 198 Volt dari tegangan nominal jaringan tegangan rendah yaitu $220 \mathrm{~V}$.

Pada jurnal ini lokasi penelitian yang mengalami gangguan voltage drop yaitu pada Desa Pakandangan Tengah. Menurut laporan yang diterima oleh PT PLN (Persero) UP3 Pamekasan terdapat banyak keluhan dari masyarakat telah terjadinya voltage drop pada daerah tersebut. Akibat voltage drop tersebut mengakibatkan gangguan pada alat-alat elektronik yang tidak bisa dioperasikan serta nyala lampu mengalami redup. Permasalahan dari voltage drop ini tentu saja harus segera diselesaikan dan diperbaiki, hal ini bukan hanya karena kepuasan pelanggan PLN tetapi juga agar nilai tegangan yang terjadi di desa tersebut bisa berada pada nilai ideal yang sudah ditentukan oleh SPLN yaitu $+-10 \%$ atau minimum 198 volt dari nilai ideal 220 Volt. [1] [2]

Jatuh tegangan sendiri bisa disebabkan oleh beberapa faktor dan dari hasil analisa pada gardu distribusi $\mathrm{KH} 007$ penyebab utamanya yaitu ada 2, jaraknya yang terlalu jauh yakni $643 \mathrm{~m}$ dan juga beban beban tinggi yang ada didaerah tersebut. Karena itu sangat penting dilakukan adanya pecah beban agar tegangan yang disalurkan ke setiap rumah warga bisa menjadi tegangan yang lebih baik yaitu tegangan $220 \mathrm{~V}$.

\section{METODE PENELITIAN}

Seperti yang telah dijabarkan diatas tentang permasalahan voltage drop. Permasalahan ini akan menggunakan metode pecah beban sebagai solusi permasalahannya. Metode yang dilakukan dalam pengumpulan data yaitu survey langsung kelapangan di Desa Pakandangan Tengah, Sumenep pada gardu KH 007 di jurusan A. Kemudian Data data tersebut diolah agar mendapat analisa untuk permasalahan voltage drop. Untuk mengolah data tersebut rumus rumus yang digunakan adalah:

$\Delta V=V s-V r$

Dimana, $\mathrm{Vs}=$ Tegangan Kirim (Volt)

$$
\mathrm{Vr}=\text { Tegangan Terima (Volt) }
$$

$\Delta V=I . L(R \operatorname{Cos} \varphi+X \operatorname{Sin} \varphi)$

$\mathrm{I}=$ beban dalam Ampere

$\mathrm{L}=$ jarak antar tiang $(\mathrm{km})$

$\mathrm{R}=$ resistansi pada penghantar $(\mathrm{Ohm} / \mathrm{km})$

$\mathrm{X}=$ reaktansi pada penghantar $(\mathrm{Ohm} / \mathrm{km})$

$\operatorname{Cos} \varphi$ diasumsikan 0,85 dan $\operatorname{Sin} \varphi 0,5[3]$

$\frac{\Delta v}{V s}(\%)=\frac{V_{S}-V_{r}}{V s} \times 100 \%$

(3)

$\Delta V(\%)=$ presentase jatuh tegangan dalam persen [4] 
Vol. 10, No. 2, Desember 2020, P-ISSN 2356-1505, E-ISSN 2656-9175

https://doi.org/10.33322/sutet.v10i2.1306

Kemudian data data tegangan dan beban yang didapatkan pada lokasi penelitian bisa dilihat pada tabel dibawah :

Tabel 1. Hasil Pengukuran di Gardu KH 007 Jurusan $A$

\begin{tabular}{|c|c|c|c|c|c|c|c|c|c|}
\hline \multicolumn{5}{|c|}{ Tegangan (V) } & \multicolumn{4}{c|}{ ARUS (A) } \\
\hline R & S & T & R-S & S-T & R-T & R & S & T & N \\
\hline 214 & 223 & 218 & 386 & 397 & 375 & 138 & 91 & 133 & 59 \\
\hline
\end{tabular}

Tabel 2. Hasil Pengukuran Tegangan di Tiang Terakhir Desa Pakandangan Tengah, Sumenep

\begin{tabular}{|c|l|l|}
\hline $\begin{array}{l}\mathrm{R}- \\
\mathrm{N}(\mathrm{V})\end{array}$ & $\begin{array}{l}\text { S-N } \\
(\mathrm{V})\end{array}$ & $\begin{array}{l}\text { T-N } \\
(\mathrm{V})\end{array}$ \\
\hline 189 & 206 & 194 \\
\hline
\end{tabular}

Tabel 3. Karakteristik Kabel TIC (NFA2X) sesuai dengan SPLN 42-10 :1993 [5]

\begin{tabular}{|c|c|c|c|}
\hline \multicolumn{2}{|c|}{ Penghantar } & $\begin{array}{c}\text { Resistansi } \\
\text { penghantar pada } \\
20^{\circ}(\mathrm{ohm} / \mathrm{km})\end{array}$ & $\begin{array}{c}\text { Reaktansi pada } \mathrm{f}= \\
50 \mathrm{~Hz}(\mathrm{ohm} / \mathrm{km})\end{array}$ \\
\hline Jenis & Ukuran & & 0,1 \\
\hline NFA2X & $\begin{array}{l}3 \times 70 \mathrm{~mm}^{2}+1 \mathrm{x} \\
50 \mathrm{~mm}^{2}\end{array}$ & 0,443 & 0 \\
\hline
\end{tabular}

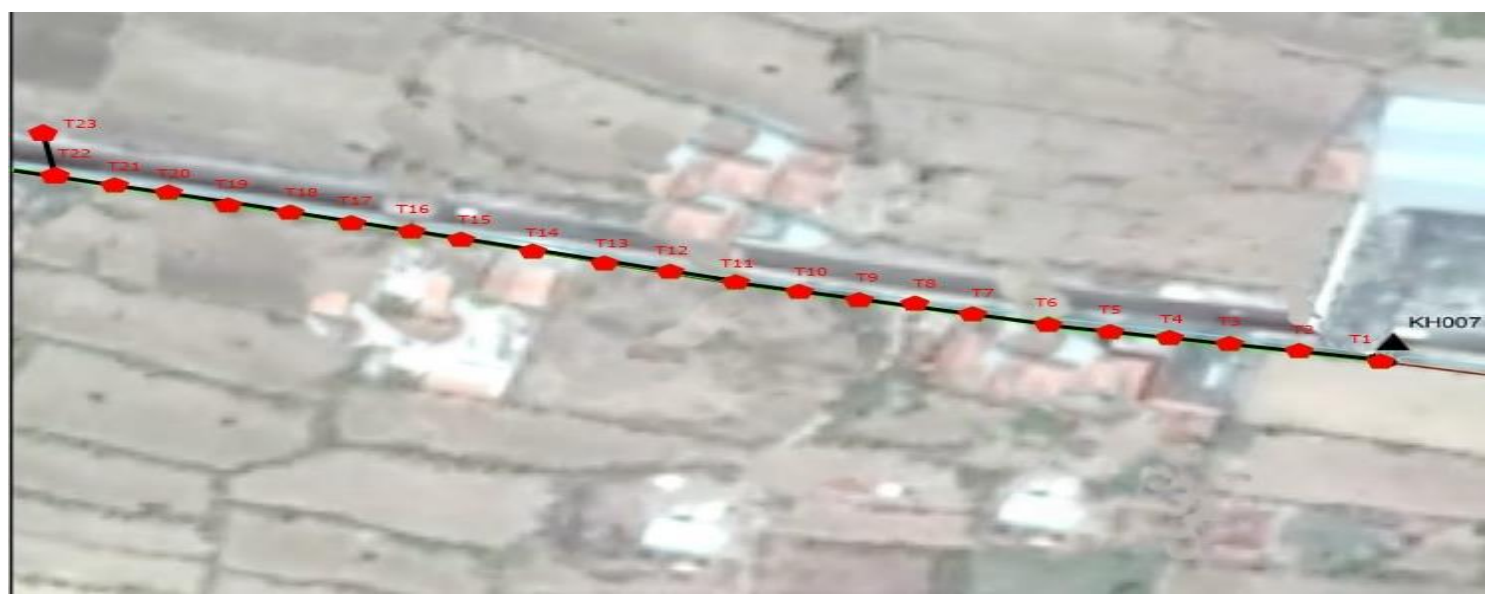

Gambar 1. Lokasi Jurusan A pada Desa Pakandangan Tengah, Sumenep 


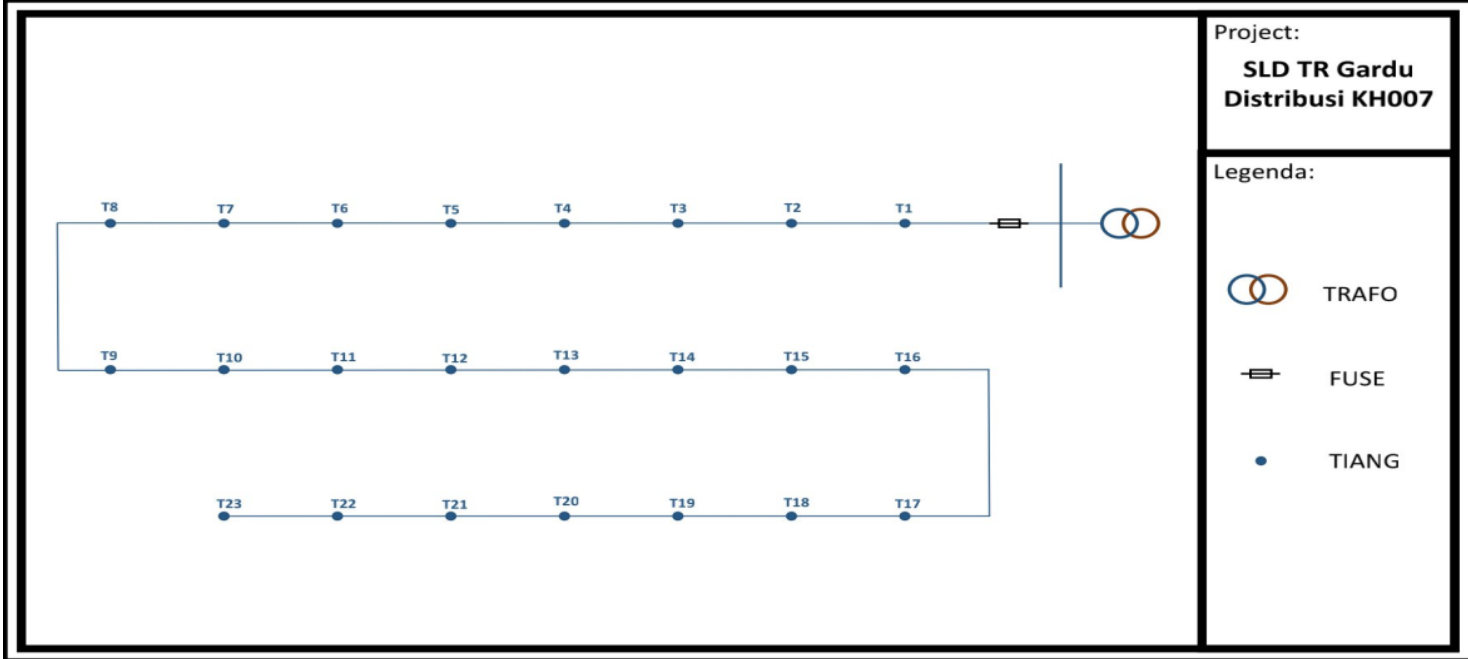

Gambar 2. Single Line Diagram Gardu KH 007

\section{HASIL DAN PEMBAHASAN}

Hasil analisa yang didapat pada data data diatas bisa dilihat pada tabel dibawah ini :

Tabel 4. Total Daya Tersambung Tiap Tiang

\begin{tabular}{|c|c|c|c|}
\hline \multicolumn{4}{|c|}{ Daya Tersambung (VA) } \\
\hline Tiang & $\mathrm{R}$ & $\mathrm{S}$ & $\mathrm{T}$ \\
\hline $\mathrm{T} 1$ & 900 & 1300 & 900 \\
\hline $\mathrm{T} 2$ & 2200 & 900 & 1300 \\
\hline $\mathrm{T} 3$ & 1300 & 1300 & 900 \\
\hline $\mathrm{T} 4$ & 2200 & 900 & 2200 \\
\hline $\mathrm{T} 5$ & 1300 & 900 & 1300 \\
\hline $\mathrm{T} 6$ & 900 & 1300 & 900 \\
\hline $\mathrm{T} 7$ & 1300 & 900 & 1300 \\
\hline $\mathrm{T} 8$ & 2200 & 3500 & 900 \\
\hline $\mathrm{T} 9$ & 900 & 1300 & 2200 \\
\hline $\mathrm{T} 10$ & 3500 & 900 & 900 \\
\hline $\mathrm{T} 11$ & 900 & 900 & 2200 \\
\hline $\mathrm{T} 12$ & 1300 & 900 & 1300 \\
\hline $\mathrm{T} 13$ & 3500 & 900 & 2200 \\
\hline $\mathrm{T} 14$ & 1300 & 1300 & 900 \\
\hline $\mathrm{T} 15$ & 900 & 1300 & 900 \\
\hline $\mathrm{T} 16$ & 3500 & 900 & 2200 \\
\hline $\mathrm{T} 17$ & 2200 & 900 & 900 \\
\hline $\mathrm{T} 18$ & 2200 & 1300 & 1300 \\
\hline $\mathrm{T} 19$ & 3500 & 900 & 3500 \\
\hline $\mathrm{T} 20$ & 4400 & 2200 & 3500 \\
\hline $\mathrm{T} 21$ & 4400 & 3500 & 3500 \\
\hline $\mathrm{T} 22$ & 4400 & 4400 & 4400 \\
\hline $\mathrm{T} 23$ & 4400 & 4400 & 4400 \\
\hline & & & \\
\hline
\end{tabular}


Untuk menghitung jatuh tegangan di masing-masing tiang dapat menggunakan persamaan (2) diatas. Jarak antar tiang $(\mathrm{L})$ memiliki rata rata 29 meter $(0,029 \mathrm{~km})$. Arus pada tiang dihitung dengan perbandingan antara total daya tersambung pada tiang ke-n dengan total daya pada fasa tersebut. [6]

Perhitungan arus tiang pada fasa $R$ dengan daya total yang ada pada tabel (4) diatas adalah 53600 VA dan arus yang terukur seperti ditunjukkan dalam tabel (1) adalah $138 \mathrm{~A}$, maka diperoleh:

$$
\begin{array}{ll}
\text { Arus pada tiang } 1 & I_{1}=\frac{900}{53600} \times 138 \mathrm{~A}=2,317 \mathrm{~A} \\
\text { Arus pada tiang 2 } & I_{2}=\frac{2200}{53600} \times 138 \mathrm{~A}=5,664 \mathrm{~A}
\end{array}
$$

Perhitungan arus tiap tiang selanjutnya dilakukan dengan perhitungan persamaan yang sama.

Selanjutnya mencari arus saluran. Arus saluran adalah arus beban puncak yang diukur pada rak TR gardu $\mathrm{KH} 007$ yaitu untuk fasa $\mathrm{R}, \mathrm{I}=138 \mathrm{~A}$. Kemudian untuk menghitung arus saluran pada tiap tiap tiang selanjutnya dapat menggunakan persamaan berikut :

Arus Saluran 2

Arus Saluran 3

$$
I_{S 2}=I_{S 1}-I_{1}=138 A-2,317=135,68
$$

$$
I_{S 3}=I_{S 2}-I_{2}=135,68 A-5,66=130,02
$$

Perhitungan arus saluran selanjutnya menggunakan persamaan yang sama dan hasilnya dapat dilihat pada tabel 5 dibawah.

Perhitungan jatuh tegangan dimasing masing tiang dari tiang pertama hingga tiang terakhir yang mengalami jatuh tegangan. Perhitungan ini menggunakan nilai yang telah dihitung sebelumnya. Berikut adalah perhitungan jatuh tegangan tiap tiang dengan menggunakan (2) :

Jatuh tegangan pada tiang 1

$$
\begin{aligned}
& \Delta V_{1}=I_{S 1} L(R \operatorname{Cos} \varphi+X \operatorname{Sin} \varphi) \\
& \Delta V_{1}=138 \times 0,005(0,443 \times 0,85+0,1 \times 0,5) \\
& \Delta V_{1}=0,294 \mathrm{~V}
\end{aligned}
$$

Nilai L pada $\Delta V_{1}$ adalah jarak dari gardu ke tiang pertama Jatuh tegangan pada tiang 2

$$
\begin{aligned}
& \Delta V_{2}=I_{S 2} L(R \operatorname{Cos} \varphi+\operatorname{Sin} \varphi) \\
& \Delta V_{2}=135,68 \times 0,029(0,443 \times 0,85+0,1 \times 0,5) \\
& \Delta V_{2}=1,763 \mathrm{~V}
\end{aligned}
$$

Jatuh tegangan pada tiang 3

$$
\begin{aligned}
& \Delta V_{3}=I_{S 3} L(R \operatorname{Cos} \varphi+\operatorname{Sin} \varphi) \\
& \Delta V_{3}=130,02 \times 0,029 \times(0,443 \times 0,85+0,1 \times 0,5) \\
& \Delta V_{3}=1,69 \mathrm{~V}
\end{aligned}
$$

Perhitungan jatuh tegangan pada tiang tiang berikutnya menggunakan persamaan yang sama. Selanjutnya menghitung tegangan pada masing masing tiang dengan persamaan berikut :

Tegangan pada tiang 1

$$
V_{1}=V_{S}-\Delta V_{1}=214-0,294=213,71 \mathrm{~V}
$$


Tegangan pada tiang 2

$$
V_{2}=V_{1}-\Delta V_{2}=213,71-1,763=211,94 \mathrm{~V}
$$

Tegangan pada tiang 3

$$
V_{3}=V_{2}-\Delta V_{3}=211,94-1,69=210,25 \mathrm{~V}
$$

$V_{1}$ adalah tegangan pada tiang $1, V_{S}$ adalah tegangan kirim yang terukur di rak TR gardu $\mathrm{KH} 007$ dan $\Delta V$ adalah hasil perhitungan jatuh tegangan pada perhitungan sebelumnya. Perhitungan tegangan tiang berikutnya dilakukan dengan menggunakan persamaan yang sama dan hasilnya dapat dilihat pada tabel 5 dibawah.

\begin{tabular}{|c|c|c|c|c|c|c|}
\hline \multicolumn{7}{|c|}{ FASA R } \\
\hline Tiang & $\begin{array}{c}\text { Daya } \\
\text { Tersambung } \\
\text { (VA) }\end{array}$ & $\begin{array}{l}\text { Arus } \\
\text { Pada } \\
\text { Tiang } \\
\text { (A) }\end{array}$ & $\begin{array}{c}\text { Arus } \\
\text { Saluran } \\
\text { (A) }\end{array}$ & $\begin{array}{c}\text { Jatuh } \\
\text { Tegangan } \\
\text { (V) }\end{array}$ & $\begin{array}{c}\text { Tegangan } \\
\text { (V) }\end{array}$ & $\begin{array}{l}\text { Presentase } \\
\text { Jatuh } \\
\text { Tegangan } \\
(\%)\end{array}$ \\
\hline T1 & 900 & 2,317 & 138,000 & 0,294 & 213,706 & 0,14 \\
\hline T2 & 2200 & 5,664 & 135,683 & 1,764 & 211,942 & 0,96 \\
\hline T3 & 1300 & 3,347 & 130,019 & 1,690 & 210,252 & 1,75 \\
\hline $\mathrm{T} 4$ & 2200 & 5,664 & 126,672 & 1,647 & 208,605 & 2,52 \\
\hline T5 & 1300 & 3,347 & 121,007 & 1,573 & 207,032 & 3,26 \\
\hline T6 & 900 & 2,317 & 117,660 & 1,530 & 205,502 & 3,97 \\
\hline T7 & 1300 & 3,347 & 115,343 & 1,499 & 204,003 & 4,67 \\
\hline T8 & 2200 & 5,664 & 111,996 & 1,456 & 202,547 & 5,35 \\
\hline T9 & 900 & 2,317 & 106,332 & 1,382 & 201,165 & 6,00 \\
\hline $\mathrm{T} 10$ & 3500 & 9,011 & 104,015 & 1,352 & 199,813 & 6,63 \\
\hline $\mathrm{T} 11$ & 900 & 2,317 & 95,004 & 1,235 & 198,577 & 7,21 \\
\hline $\mathrm{T} 12$ & 1300 & 3,347 & 92,687 & 1,205 & 197,373 & 7,77 \\
\hline T13 & 3500 & 9,011 & 89,340 & 1,161 & 196,211 & 8,31 \\
\hline T14 & 1300 & 3,347 & 80,328 & 1,044 & 195,167 & 8,80 \\
\hline T15 & 900 & 2,317 & 76,981 & 1,001 & 194,166 & 9,27 \\
\hline T16 & 3500 & 9,011 & 74,664 & 0,971 & 193,195 & 9,72 \\
\hline T17 & 2200 & 5,664 & 65,653 & 0,853 & 192,342 & 10,12 \\
\hline T18 & 2200 & 5,664 & 59,989 & 0,780 & 191,562 & 10,48 \\
\hline T19 & 3500 & 9,011 & 54,325 & 0,706 & 190,856 & 10,81 \\
\hline T20 & 4400 & 11,328 & 45,313 & 0,589 & 190,267 & 11,09 \\
\hline T21 & 4400 & 11,328 & 33,985 & 0,442 & 189,825 & 11,30 \\
\hline T22 & 4400 & 11,328 & 22,657 & 0,295 & 189,531 & 11,43 \\
\hline T23 & 4400 & 11,328 & 11,328 & 0,147 & 189,383 & 11,50 \\
\hline
\end{tabular}

Tabel 5. Hasil Perhitungan Jatuh Tegangan pada Fasa R Tiap Tiang JTR saat Beban Puncak

Untuk perhitungan fasa $\mathrm{S}$, dan $\mathrm{T}$ sama seperti tabel 5 diatas dan diperoleh hasil seperti pada tabel 6 dan tabel 7 berikut : 
Vol. 10, No. 2, Desember 2020, P-ISSN 2356-1505, E-ISSN 2656-9175 https://doi.org/10.33322/sutet.v10i2.1306

Tabel 6. Hasil Perhitungan Jatuh Tegangan pada Fasa S Tiap Tiang JTR saat Beban Puncak

\begin{tabular}{|c|c|c|c|c|c|c|}
\hline \multicolumn{7}{|c|}{ FASA S } \\
\hline Tiang & $\begin{array}{c}\text { Daya } \\
\text { Tersambung } \\
\text { (VA) }\end{array}$ & $\begin{array}{l}\text { Arus } \\
\text { Pada } \\
\text { Tiang } \\
\text { (A) }\end{array}$ & $\begin{array}{l}\text { Arus } \\
\text { Saluran } \\
\text { (A) }\end{array}$ & $\begin{array}{c}\text { Jatuh } \\
\text { Tegangan } \\
\text { (V) }\end{array}$ & $\begin{array}{c}\text { Tegangan } \\
\text { (V) }\end{array}$ & $\begin{array}{c}\text { Presentase } \\
\text { Jatuh } \\
\text { Tegangan } \\
(\%)\end{array}$ \\
\hline T1 & 1300 & 3,197 & 91,000 & 0,194 & 222,806 & 0,087 \\
\hline T2 & 900 & 2,214 & 87,803 & 1,141 & 221,665 & 0,599 \\
\hline T3 & 1300 & 3,197 & 85,589 & 1,113 & 220,552 & 1,098 \\
\hline T4 & 900 & 2,214 & 82,392 & 1,071 & 219,481 & 1,578 \\
\hline T5 & 900 & 2,214 & 80,178 & 1,042 & 218,438 & 2,046 \\
\hline T6 & 1300 & 3,197 & 77,965 & 1,014 & 217,425 & 2,500 \\
\hline T7 & 900 & 2,214 & 74,768 & 0,972 & 216,453 & 2,936 \\
\hline T8 & 3500 & 8,608 & 72,554 & 0,943 & 215,510 & 3,359 \\
\hline T9 & 1300 & 3,197 & 63,946 & 0,831 & 214,678 & 3,732 \\
\hline T10 & 900 & 2,214 & 60,749 & 0,790 & 213,889 & 4,086 \\
\hline $\mathrm{T} 11$ & 900 & 2,214 & 58,535 & 0,761 & 213,128 & 4,427 \\
\hline T12 & 900 & 2,214 & 56,322 & 0,732 & 212,396 & 4,755 \\
\hline T13 & 900 & 2,214 & 54,108 & 0,703 & 211,692 & 5,071 \\
\hline T14 & 1300 & 3,197 & 51,895 & 0,675 & 211,018 & 5,373 \\
\hline T15 & 1300 & 3,197 & 48,697 & 0,633 & 210,385 & 5,657 \\
\hline T16 & 900 & 2,214 & 45,500 & 0,592 & 209,793 & 5,922 \\
\hline T17 & 900 & 2,214 & 43,286 & 0,563 & 209,230 & 6,175 \\
\hline T18 & 1300 & 3,197 & 41,073 & 0,534 & 208,696 & 6,414 \\
\hline T19 & 900 & 2,214 & 37,876 & 0,492 & 208,204 & 6,635 \\
\hline T20 & 2200 & 5,411 & 35,662 & 0,464 & 207,740 & 6,843 \\
\hline T21 & 3500 & 8,608 & 30,251 & 0,393 & 207,347 & 7,019 \\
\hline T22 & 4400 & 10,822 & 21,643 & 0,281 & 207,066 & 7,145 \\
\hline T23 & 4400 & 10,822 & 10,822 & 0,141 & 206,925 & 7,209 \\
\hline
\end{tabular}

Tabel 7. Hasil Perhitungan Jatuh Tegangan pada Fasa T Tiap Tiang JTR saat Beban Puncak

\begin{tabular}{|c|c|c|c|c|c|c|}
\hline \multicolumn{7}{|c|}{ FASA T } \\
\hline Tiang & $\begin{array}{c}\text { Daya } \\
\text { Tersambung } \\
\text { (VA) }\end{array}$ & $\begin{array}{c}\text { Arus } \\
\text { Pada } \\
\text { Tiang } \\
\text { (A) }\end{array}$ & $\begin{array}{c}\text { Arus } \\
\text { Saluran } \\
\text { (A) }\end{array}$ & $\begin{array}{c}\text { Jatuh } \\
\text { Tegangan } \\
\text { (V) }\end{array}$ & $\begin{array}{c}\text { Tegangan } \\
\text { (V) }\end{array}$ & $\begin{array}{c}\text { Presentase } \\
\text { Jatuh } \\
\text { Tegangan } \\
(\%)\end{array}$ \\
\hline T1 & 900 & 2,720 & 133,000 & 0,313 & 217,687 & 0,144 \\
\hline T2 & 1300 & 3,930 & 130,280 & 1,694 & 215,993 & 0,920 \\
\hline T3 & 900 & 2,720 & 126,350 & 1,643 & 214,351 & 1,674 \\
\hline T4 & 2200 & 6,650 & 123,630 & 1,607 & 212,744 & 2,411 \\
\hline T5 & 1300 & 3,930 & 116,980 & 1,521 & 211,223 & 3,109 \\
\hline T6 & 900 & 2,720 & 113,050 & 1,470 & 209,753 & 3,783 \\
\hline T7 & 1300 & 3,930 & 110,330 & 1,434 & 208,319 & 4,441 \\
\hline T8 & 900 & 2,720 & 106,400 & 1,383 & 206,936 & 5,075 \\
\hline T9 & 2200 & 6,650 & 103,680 & 1,348 & 205,588 & 5,694 \\
\hline
\end{tabular}




\begin{tabular}{|c|c|c|c|c|c|c|} 
T10 & 900 & 2,720 & 97,030 & 1,261 & 204,327 & 6,272 \\
\hline T11 & 2200 & 6,650 & 94,309 & 1,226 & 203,101 & 6,835 \\
\hline T12 & 1300 & 3,930 & 87,659 & 1,140 & 201,961 & 7,357 \\
\hline T13 & 2200 & 6,650 & 83,730 & 1,088 & 200,872 & 7,857 \\
\hline T14 & 900 & 2,720 & 77,080 & 1,002 & 199,870 & 8,316 \\
\hline T15 & 900 & 2,720 & 74,359 & 0,967 & 198,904 & 8,760 \\
\hline T16 & 2200 & 6,650 & 71,639 & 0,931 & 197,972 & 9,187 \\
\hline T17 & 900 & 2,720 & 64,989 & 0,845 & 197,128 & 9,574 \\
\hline T18 & 1300 & 3,930 & 62,268 & 0,809 & 196,318 & 9,946 \\
\hline T19 & 3500 & 10,580 & 58,339 & 0,758 & 195,560 & 10,294 \\
\hline T20 & 3500 & 10,580 & 47,759 & 0,621 & 194,939 & 10,579 \\
\hline T21 & 3500 & 10,580 & 37,180 & 0,483 & 194,456 & 10,800 \\
\hline T22 & 4400 & 13,300 & 26,600 & 0,346 & 194,110 & 10,959 \\
\hline T23 & 4400 & 13,300 & 13,300 & 0,173 & 193,937 & 11,038 \\
\hline
\end{tabular}

Pecah beban dilakukan untuk mengurangi jatuh tegangan yang terjadi pada jurusan ini. Metode pecah beban yang dilakukan yaitu memindah beban dari 5 tiang terakhir menjadi jurusan yang baru. Persamaan yang digunakan sama halnya dengan persamaan rumus $R, S$ dan $T$ saat sebelum diadakannya pecah beban. Data hasil pecah beban menjadi 5 tiang yang baru dapat dilihat pada tabel 8 , tabel 9 , dan tabel 10 di bawah:

Tabel 8. Hasil Perhitungan Jatuh Tegangan pada Fasa R Tiap Tiang JTR saat Beban Puncak

\begin{tabular}{|c|c|c|c|c|c|c|}
\hline \multicolumn{7}{|c|}{ FASA R } \\
\hline Tiang & $\begin{array}{c}\text { Daya } \\
\text { Tersambung } \\
\text { (VA) }\end{array}$ & $\begin{array}{l}\text { Arus } \\
\text { Pada } \\
\text { Tiang } \\
\text { (A) }\end{array}$ & $\begin{array}{c}\text { Arus } \\
\text { Saluran } \\
\text { (A) }\end{array}$ & $\begin{array}{c}\text { Jatuh } \\
\text { Tegangan } \\
\text { (V) }\end{array}$ & $\begin{array}{c}\text { Tegangan } \\
\text { Terima } \\
\text { (V) }\end{array}$ & $\begin{array}{l}\text { Presentase } \\
\text { Jatuh } \\
\text { Tegangan } \\
(\%)\end{array}$ \\
\hline T19 & 3500 & 8,957 & 54,000 & 12,692 & 201,308 & 5,931 \\
\hline T20 & 4400 & 11,261 & 45,043 & 0,557 & 200,751 & 6,191 \\
\hline T21 & 4400 & 11,261 & 33,782 & 0,418 & 200,333 & 6,386 \\
\hline T22 & 4400 & 11,261 & 22,521 & 0,279 & 200,055 & 6,516 \\
\hline T23 & 4400 & 11,261 & 11,261 & 0,139 & 199,915 & 6,582 \\
\hline
\end{tabular}

Tabel 9. Hasil Perhitungan Jatuh Tegangan pada Fasa S Tiap Tiang JTR saat Beban Puncak

\begin{tabular}{|c|c|c|c|c|c|c|}
\hline \multicolumn{7}{|c|}{ FASA S } \\
\hline Tiang & $\begin{array}{c}\text { Daya } \\
\text { Tersambung } \\
(\mathrm{VA})\end{array}$ & $\begin{array}{c}\text { Arus } \\
\text { Pada } \\
\text { Tiang } \\
(\mathrm{A})\end{array}$ & $\begin{array}{c}\text { Arus } \\
\text { Saluran } \\
(\mathrm{A})\end{array}$ & $\begin{array}{c}\text { Jatuh } \\
\text { Tegangan } \\
(\mathrm{V})\end{array}$ & $\begin{array}{c}\text { Tegangan } \\
\text { Terima } \\
(\mathrm{V})\end{array}$ & $\begin{array}{c}\text { Presentase } \\
\text { Jatuh } \\
\text { Tegangan } \\
(\%)\end{array}$ \\
\hline T19 & 900 & 2,221 & 38,000 & 8,931 & 214,069 & 4,005 \\
\hline T20 & 2200 & 5,429 & 35,779 & 0,443 & 213,626 & 4,203 \\
\hline T21 & 3500 & 8,636 & 30,351 & 0,375 & 213,251 & 4,372 \\
\hline T22 & 4400 & 10,857 & 21,714 & 0,269 & 212,982 & 4,492 \\
\hline T23 & 4400 & 10,857 & 10,857 & 0,134 & 212,848 & 4,552 \\
\hline
\end{tabular}


Vol. 10, No. 2, Desember 2020, P-ISSN 2356-1505, E-ISSN 2656-9175

https://doi.org/10.33322/sutet.v10i2.1306

Tabel 10. Hasil Perhitungan Jatuh Tegangan pada Fasa R Tiap Tiang JTR saat Beban Puncak

\begin{tabular}{|c|c|c|c|c|c|c|}
\hline \multicolumn{7}{|c|}{ FASA T } \\
\hline Tiang & $\begin{array}{c}\text { Daya } \\
\text { Tersambung } \\
(\mathrm{VA})\end{array}$ & $\begin{array}{c}\text { Arus } \\
\text { Pada } \\
\text { Tiang } \\
(\mathrm{A})\end{array}$ & $\begin{array}{c}\text { Arus } \\
\text { Saluran } \\
(\mathrm{A})\end{array}$ & $\begin{array}{c}\text { Jatuh } \\
\text { Tegangan } \\
(\mathrm{V})\end{array}$ & $\begin{array}{c}\text { Tegangan } \\
\text { Terima } \\
(\mathrm{V})\end{array}$ & $\begin{array}{c}\text { Presentase } \\
\text { Jatuh } \\
\text { Tegangan } \\
(\%)\end{array}$ \\
\hline T19 & 3500 & 10,518 & 58,000 & 13,632 & 204,368 & 6,253 \\
\hline T20 & 3500 & 10,518 & 47,482 & 0,587 & 203,781 & 6,522 \\
\hline T21 & 3500 & 10,518 & 36,964 & 0,457 & 203,324 & 6,732 \\
\hline T22 & 4400 & 13,223 & 26,446 & 0,327 & 202,997 & 6,882 \\
\hline T23 & 4400 & 13,223 & 13,223 & 0,164 & 202,833 & 6,957 \\
\hline
\end{tabular}

Load flow Gardu KH 007 dengan simulasi menggunakan software ETAP dapat dilihat pada Gambar 3 di bawah:[7]

One-Line Diagram - OLV1 (Load Flow Analysis)

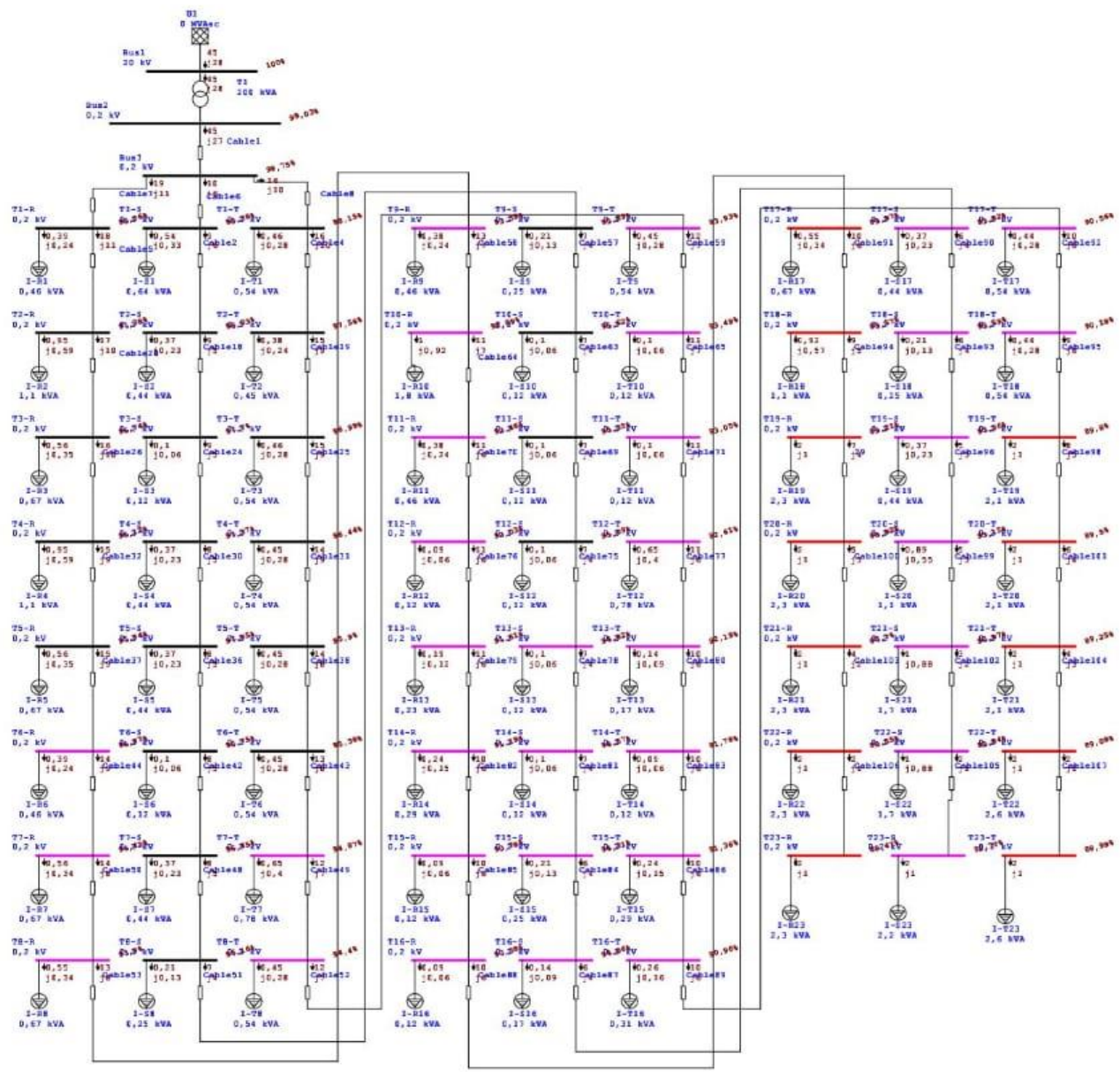

Gambar 3. Load Flow GH 007 Sebelum Pecah Beban 
Dari hasil analisa diatas menunjukan adanya beberapa bus yang mengalami jatuh tegangan dengan nilai seperti pada tabel 11 berikut :

Tabel 11. Hasil Simulasi ETAP Jaringan Sebelum Pecah Beban

\begin{tabular}{|c|c|c|c|c|c|}
\hline \multicolumn{2}{|c|}{ Fasa R } & \multicolumn{2}{c|}{ Fasa S } & \multicolumn{2}{c|}{ Fasa T } \\
\hline Tiang & $\begin{array}{c}\text { Operating } \\
\text { Bus(\%) }\end{array}$ & Tiang & $\begin{array}{c}\text { Operating } \\
\text { Bus(\%) }\end{array}$ & Tiang & $\begin{array}{c}\text { Operating } \\
\text { Bus (\%) }\end{array}$ \\
\hline T1 & 98,06 & T1 & 98,38 & T1 & 98,14 \\
\hline T2 & 97,38 & T2 & 98,03 & T2 & 97,56 \\
\hline T3 & 96,74 & T3 & 97,7 & T3 & 96,98 \\
\hline T4 & 96,12 & T4 & 97,37 & T4 & 96,43 \\
\hline T5 & 95,54 & T5 & 97,05 & T5 & 95,89 \\
\hline T6 & 94,97 & T6 & 96,75 & T6 & 95,37 \\
\hline T7 & 94,42 & T7 & 96,45 & T7 & 94,87 \\
\hline T8 & 93,89 & T8 & 96,16 & T8 & 94,39 \\
\hline T9 & 93,39 & T9 & 95,88 & T9 & 93,93 \\
\hline T10 & 92,89 & T10 & 95,61 & T10 & 93,48 \\
\hline T11 & 92,45 & T11 & 95,35 & T11 & 93,04 \\
\hline T12 & 92,03 & T12 & 95,08 & T12 & 92,6 \\
\hline T13 & 91,61 & T13 & 94,82 & T13 & 92,18 \\
\hline T14 & 91,19 & T14 & 94,56 & T14 & 91,77 \\
\hline T15 & 90,78 & T15 & 94,31 & T15 & 91,36 \\
\hline T16 & 90,38 & T16 & 94,06 & T16 & 90,95 \\
\hline T17 & 89,96 & T17 & 93,82 & T17 & 90,55 \\
\hline T18 & 89,57 & T18 & 93,58 & T18 & 90,17 \\
\hline T19 & 89,21 & T19 & 93,36 & T19 & 89,8 \\
\hline T20 & 88,92 & T20 & 93,14 & T20 & 89,49 \\
\hline T21 & 88,7 & T21 & 92,97 & T21 & 89,25 \\
\hline T22 & 88,55 & T22 & 92,84 & T22 & 89,07 \\
\hline T23 & 88,47 & T23 & 92,77 & T23 & 88,98 \\
\hline
\end{tabular}

Tabel 11 dapat dilihat nilai jatuh tegangan melewati nilai standar SPLN No.1 tahun 1978 yaitu $-10 \%$. Perbandingan nilai jatuh tegangan dengan software ETAP tidak jauh berbeda dengan perhitungan manual yaitu untuk fasa $R(11,5 \%$ \& $11,53 \%)$, fasa $S(7,209$ $\%$ \& 7,23\%), dan fasa $T(11,038 \%$ \& $11,02 \%)$.

Load flow GH 007 Setelah Pecah Beban ditunjukkan dalam Gambar 4 dengan hasil pada Tabel 12 di bawah : 


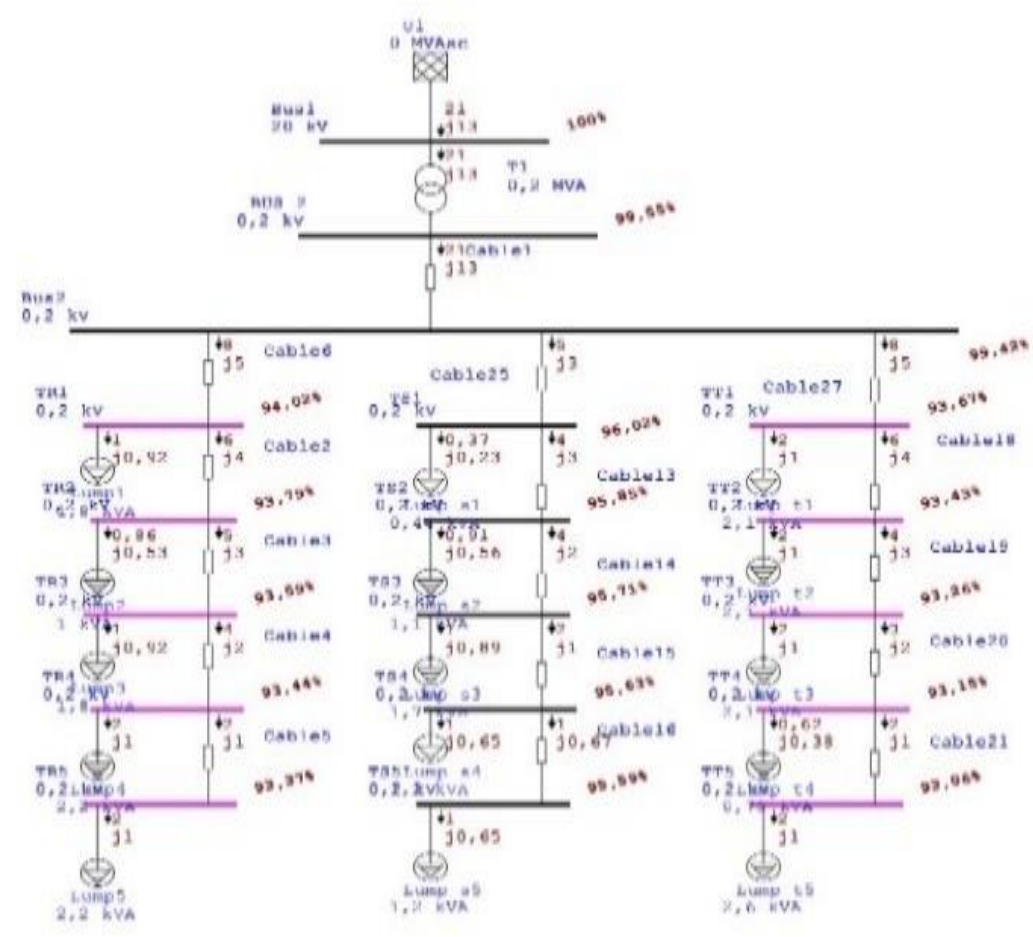

page 1 19:54:22 Feb 20, 2021 Project File denn

Tabel 12. Hasil Simulasi ETAP Setelah Pecah Beban

\begin{tabular}{|c|c|c|c|c|c|}
\hline \multicolumn{2}{|c|}{ Fasa R } & \multicolumn{2}{c|}{ Fasa S } & \multicolumn{2}{c|}{ Fasa T } \\
\hline Tiang & $\begin{array}{c}\text { Operating } \\
\text { Bus(\%) }\end{array}$ & Tiang & $\begin{array}{c}\text { Operating } \\
\text { Bus(\%) }\end{array}$ & Tiang & $\begin{array}{c}\text { Operating } \\
\text { Bus (\%) }\end{array}$ \\
\hline T1 & 94,02 & T1 & 96,02 & T1 & 93,67 \\
\hline T2 & 93,79 & T2 & 95,85 & T2 & 93,43 \\
\hline T3 & 9359 & T3 & 95,71 & T3 & 93,26 \\
\hline T4 & 93,44 & T4 & 95,63 & T4 & 93,12 \\
\hline T5 & 93,37 & T5 & 95,59 & T5 & 93,06 \\
\hline
\end{tabular}

Pada Tabel 12 dapat dilihat bahwa jatuh tegangan sudah berada diatas standar SPLN No.1 tahun 1978 untuk jaringan tegangan rendah yaitu $-10 \%$. Perbandingan hasil dari simulasi software ETAP dan perhitungan manual menunjukkan hasil yang hamper sama, yaitu fasa $R(6,582 \% \& 6,63 \%)$, fasa $S(4,552 \% \& 4,41 \%)$, dan fasa $T(6,957 \& 6,94)$. Maka dari itu kita bisa mengetahui proses metode pecah beban sukses menangani jatuh tegangan yang terjadi pada gardu KH 007 di Desa Pakandangan Tengah, Sumenep. 


\section{KESIMPULAN DAN SARAN}

Kesimpulan yang dapat diambil dari hasil penelitian diatas yaitu, metode pecah beban bisa menjadi solusi untuk memecahkan masalah jatuh tegangan. Bisa dilihat dari hasil analisa pecah beban dapat memperbaiki nilai dari tegangannya. Yang awalnya nilai tegangan di fasa R 189, fasa $S 206$, dan fasa $T$ 194Volt bisa naik menjadi di fasa $R 200$, fasa S 212, dan fasa T 202 Volt. Dan lebih baik juga bila PT PLN (Persero) membuat gardu baru agar tegangan pada tiap rumah bisa menjadi tegangan yang sesuai dengan standar SPLN 1:1978 dimana tegangan maksimum 5\% dan minimum 10\% dari tegangan nominal 220Volt.

\section{DAFTAR PUSTAKA}

[1] PT. Perusahaan Listrik Negara (Persero), SPLN 1: 1978 Tegangan Standar TR, 1978.

[2] PT. Perusahaan Listrik Negara (Persero), SPLN 1 : 1995 Tegangan-Tegangan Standar, 1995.

[3] I. Kasim, C. G. Irianto dan Fachrizal, "Perbaikan Jatuh Tegangan Feeder B KB 31P Setiabdui Jakarta degan Metode Pecah Beban," JETri, vol. 11, no. 1, pp. 107-119, 2013.

[4] Suprianto, Analisa Tegangan Jatuh Pada Jaringan Distribusi 20KV PT.PLN Area Rantau Prapat rayon Aek Kota Batu, 2018.

[5] PT. Perusahaan Listrik Negara (Persero), SPLN 42-10 : 1993 Kabel Pilin Udara Tegangan Pengenal 0,6/1 kV, 1993.

[6] R. Lazuardi, I. Hajar dan A. Junaidi, "Studi Perbaikan Jatuh Tegangan Pada Jaringan Tegangan Rendah Dengan Pemasangan Gardu Sisip di Gardu CPT 2AS Penyulang Murid, UP3 Cikokol," Institut Teknologi PLN, Jakarta, 2020.

[7] A. Effendi, A. Y. Dewi dan E. Crismas, "Analisa Drop Tegangan PT PLN (Persero) Rayon Lubuk Sikaping setelah Penambahan PLTM Guntung," Jurnal Teknik Elektro ITP, vol. 6, no. 2, pp. 199-203, 2017. 